\title{
Growing Potatoes in the Florida Home Garden ${ }^{1}$
}

\author{
Christian T. Christensen, Libby R. Rens, Jeffrey E. Pack, Lincoln Zotarelli, Chad Hutchinson, \\ Wendy Dahl, Doug Gergela, and James M. White ${ }^{2}$
}

The potato is one of America's most popular vegetables. Americans eat an average of $125 \mathrm{lb}$. of potatoes per person each year. Solanum tuberosum, the scientific name for potato, also called the Irish potato, is a cool-season crop. It is grown commercially in Florida for both fresh market and chipping in the winter and spring months when the days are warm and the nights are cool. Commercial farms supply a majority of the "new" potatoes, which are small, immature potatoes with thinner skin than full-grown potatoes, nationwide in the winter and spring months. (Fig. 1).

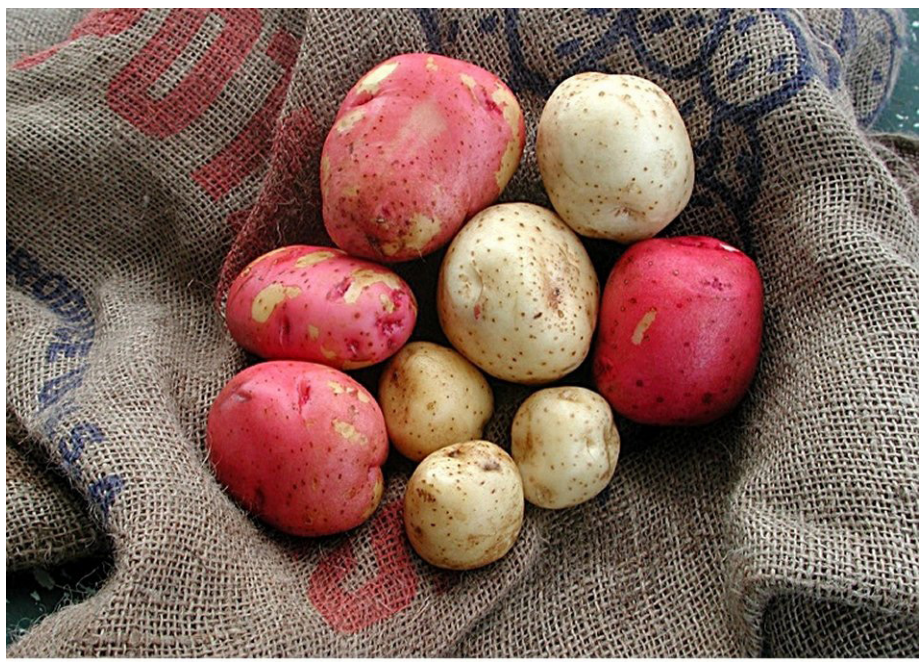

Figure 1. Red and white potatoes are grown commercially in Florida. Credits: C. Hutchinson

The same "new" potato flavor can be achieved in the home garden by following a few growing recommendations. A recently grown and harvested potato exhibits different flavor profiles from one that has been in storage or on a grocery shelf for an extended period. For example, in storage, the starches in potatoes convert to sugars, resulting in a less desirable texture and taste.

\section{Growth Cycle}

Stage 1

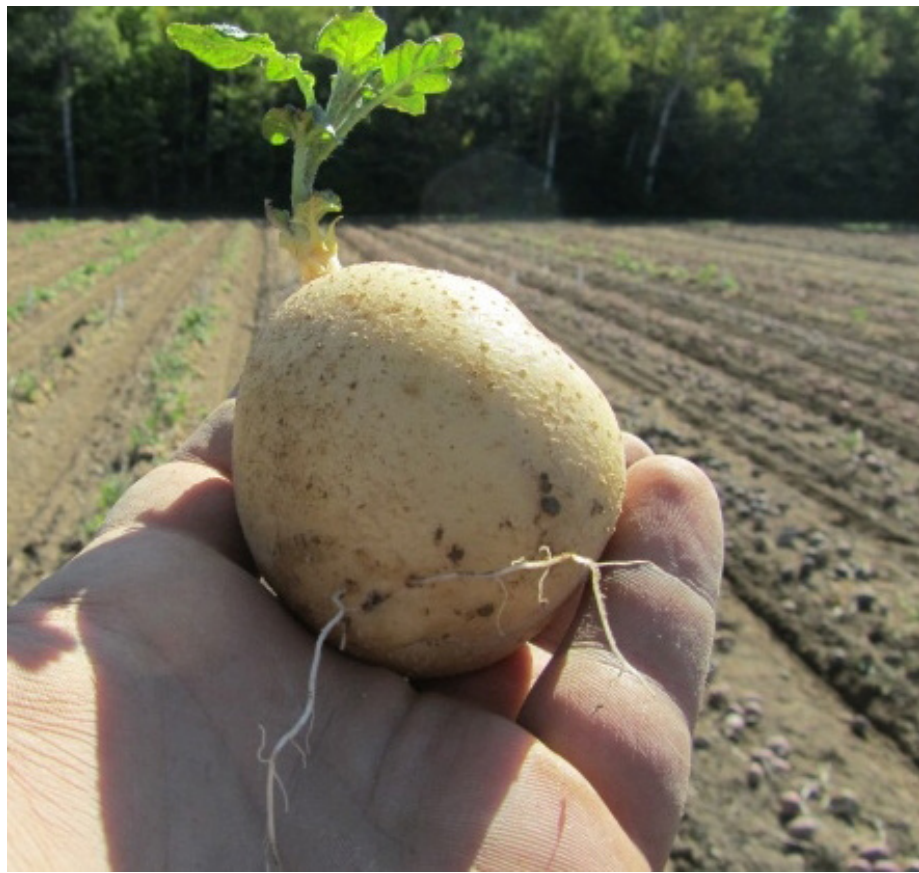

Figure 2. Sprout development (0-30 days): Potato eyes develop sprouts that emerge from the soil. The seed piece is the primary source of energy and nutrients at this stage of development. Credits: C. Christensen

1. This document is HS933, one of a series of the Horticultural Sciences Department, Florida Cooperative Extension Service, Institute of Food and Agricultural Sciences, University of Florida. Original publication date June 2003. Revised April 2013. Visit the EDIS website at http://edis.ifas.ufl.edu.

2. Christian T. Christensen and Libby R. Rens, graduate students; Jeffrey Pack, former graduate student; Lincoln Zotarelli, assistant professor; and Chad Hutchinson, former associate professor, Horticultural Sciences Department; Wendy J. Dahl, assistant professor, Food Science and Human Nutrition Department; Doug Gergela, Florida Partneship for Water and Sust. Hastings; James M. White, associate professor emeritus, MFREC-Apopka; Cooperative Extension Service, Institute of Food and Agricultural Sciences, University of Florida, Gainesville, 32611. 


\section{Stage 2}

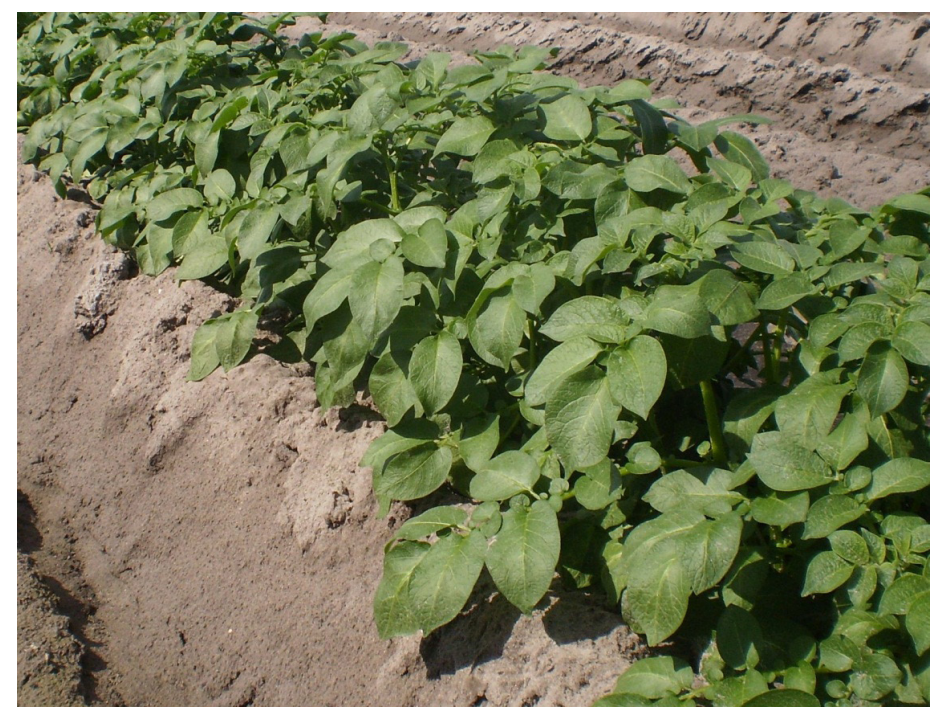

Figure 3. Vegetative growth (30-55 days): The plant leaves, stems, and root system form; photosynthesis begins; and the plant prepares for storing nutrients in tubers.

Credits: L. Zotarelli

\section{Stage 3}

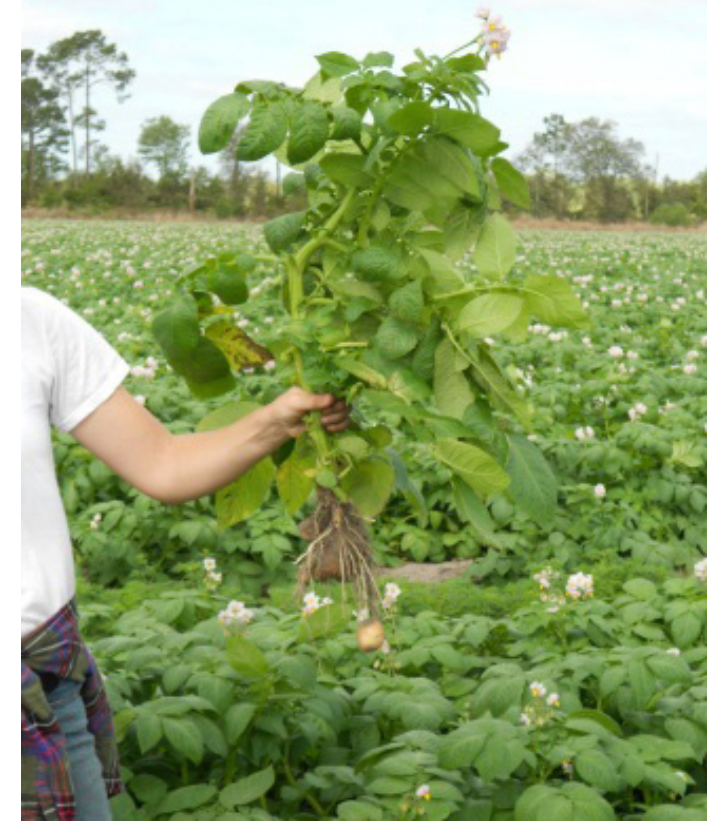

Figure 4. Tuber initiation and set (55-70 days): Tubers begin forming on the ends of stolons (underground stems), but have not enlarged. This usually happens before the plant flowers. Nutrient uptake quickly increases during this developmental stage.

Credits: L. Rens
Stage 4

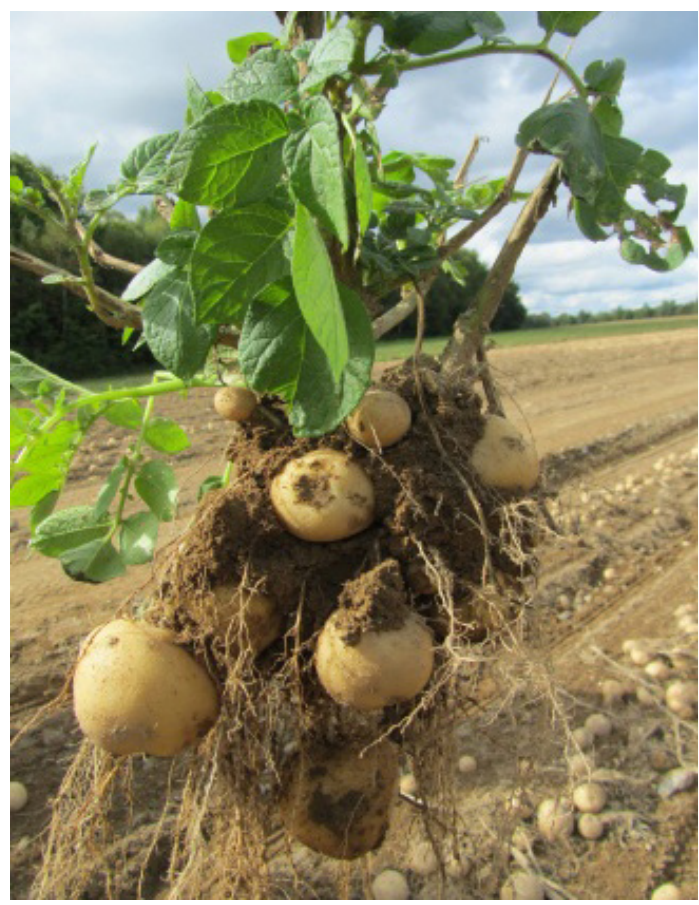

Figure 5. Tuber bulking (60-120 days, depending on variety): Tubers enlarge and sugars and starches accumulate. The rate of nutrient uptake at this time decreases.

Credits: C. Christensen

\section{Stage 5}

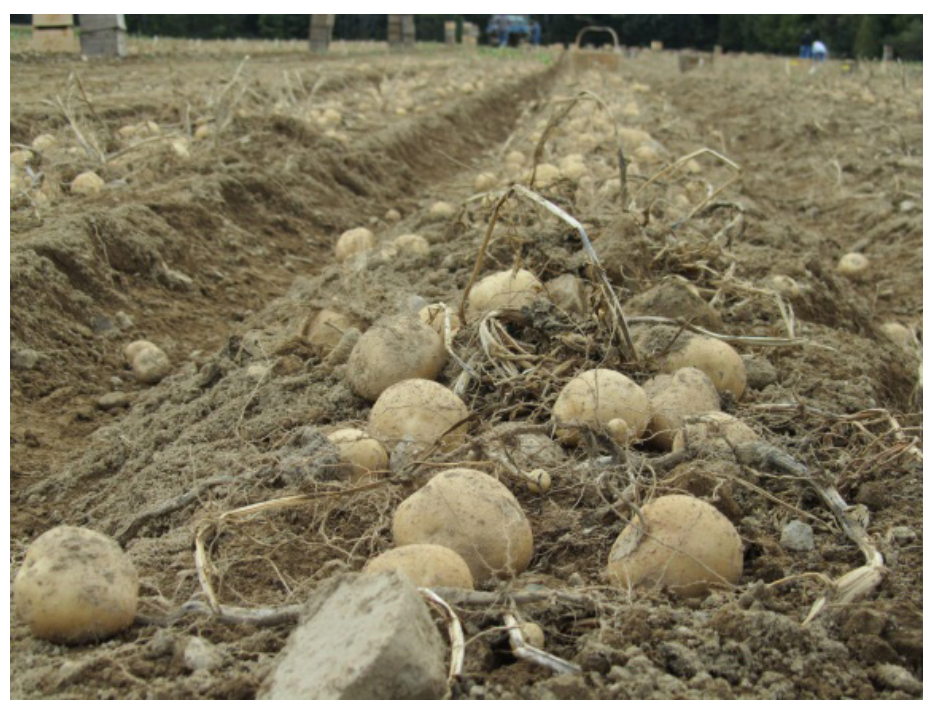

Figure 6. Tuber maturation: The tubers are at full size, and the plant top senesces (dries out) and dies. Nutrient transport to tubers continues contributing to skin toughening, which extends the storage life. Little to no nutrient uptake occurs at this point.

Credits: C. Christensen. 


\section{Varieties}

The most popular (and successful) varieties grown in Florida are based on factors such as yield, disease resistance, quality, and adaptability to warm climates. Commercial potato varieties grown in Florida can be quite different from those grown in other parts of the country. Most commercial growers in the Pacific Northwest and northern United States grow a russet-type potato, the most recognized of which is 'Russet Burbank' for french fry production and baking. However, in Florida this variety does not grow well because it takes a long time to produce tubers (up to 4 months). The late maturity makes it more susceptible to disease and pest pressures as well as inclement weather conditions. A description of popular potato varieties grown in Florida follows.

\section{White-Skinned Potatoes}

'LaChipper' (Fig. 7) is the current standard variety grown commercially in Florida. It yields well under Florida's winter growing conditions. It has a buff to white skin color with a moderately smooth skin texture and white flesh color. Tubers are mostly round with relatively deep eyes.

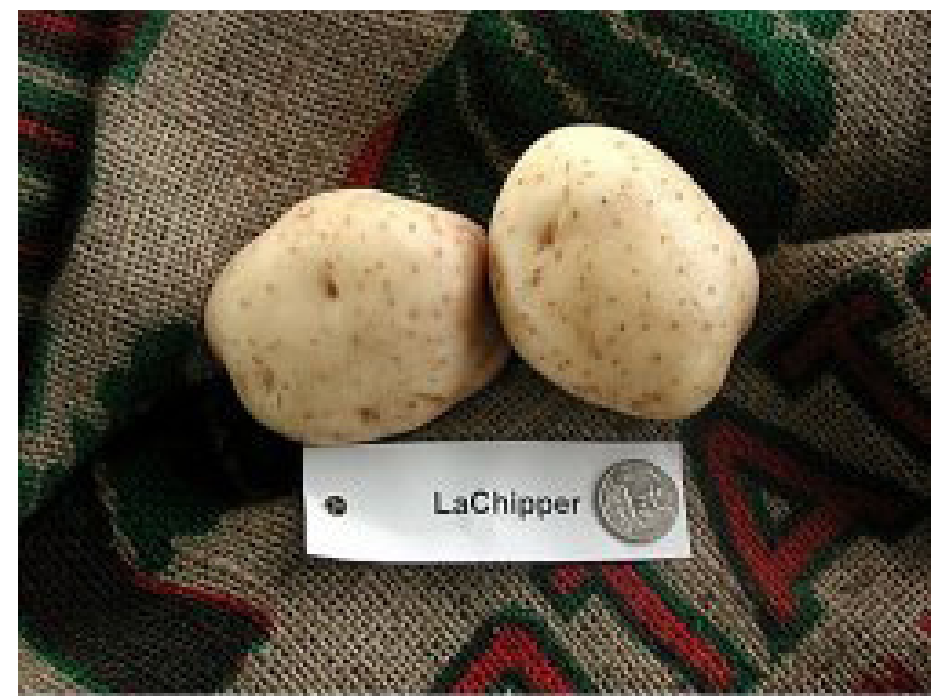

Figure 7. White-skinned potato 'LaChipper'

Credits: C. Hutchinson

'Sebago' (Fig. 8) is a traditional Florida variety with moderate yield, buff to white skin color, and a slightly netted skin texture. Tubers are round to oblong with moderately shallow eyes. This potato has exceptional flavor and has historically been recognized for its flavor.

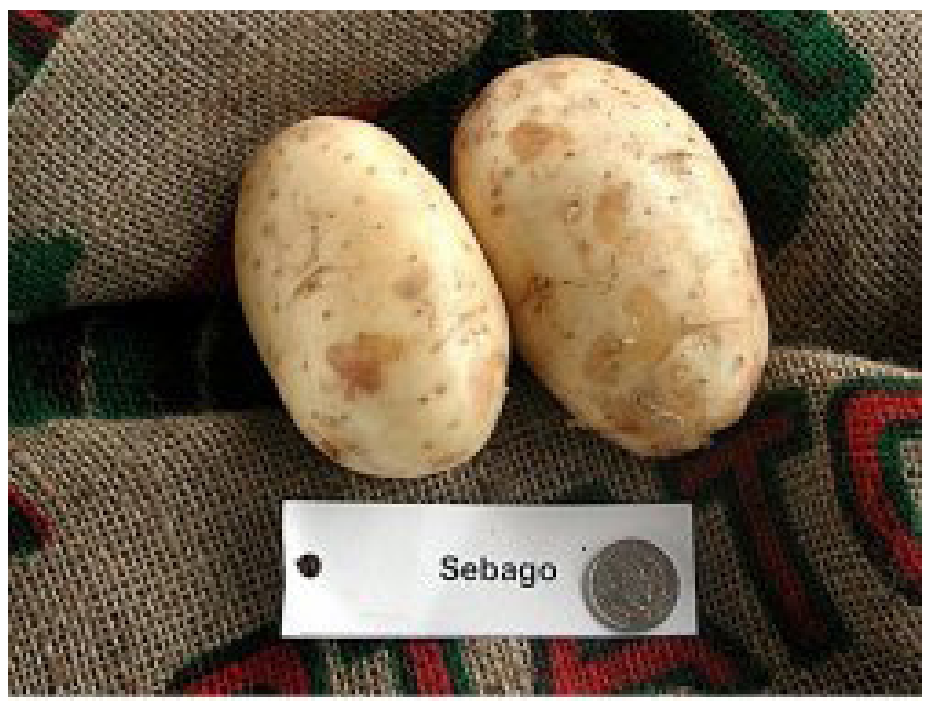

Figure 8. White-skinned potato 'Sebago' Credits: C. Hutchinson

'Yukon Gold' (Fig. 9) is a relatively new variety that can be found year-round in many grocery stores. It has moderate to high yield with yellow to white skin color and a moderately smooth skin texture. Tubers are mostly round with relatively shallow, pink eyes. 'Yukon Gold' potatoes are well known for their yellow flesh and great taste.

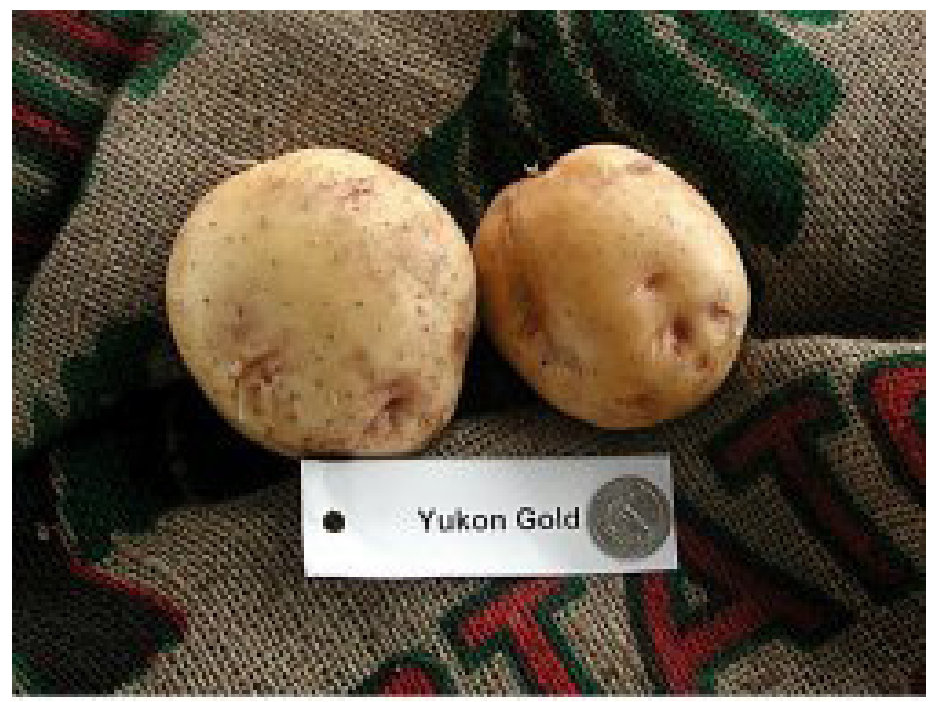

Figure 9. White-skinned potato 'Yukon Gold' Credits: C. Hutchinson

\section{Red-Skinned Potatoes}

'Red LaSoda' (Fig. 10) is the current red-skinned standard variety grown primarily in the southeastern United States and northern Florida. The plant has good yield and matures early, with harvest during the winter months for the fresh market. The tubers have bright red skin, are moderately smooth, and have relatively deep eyes. 


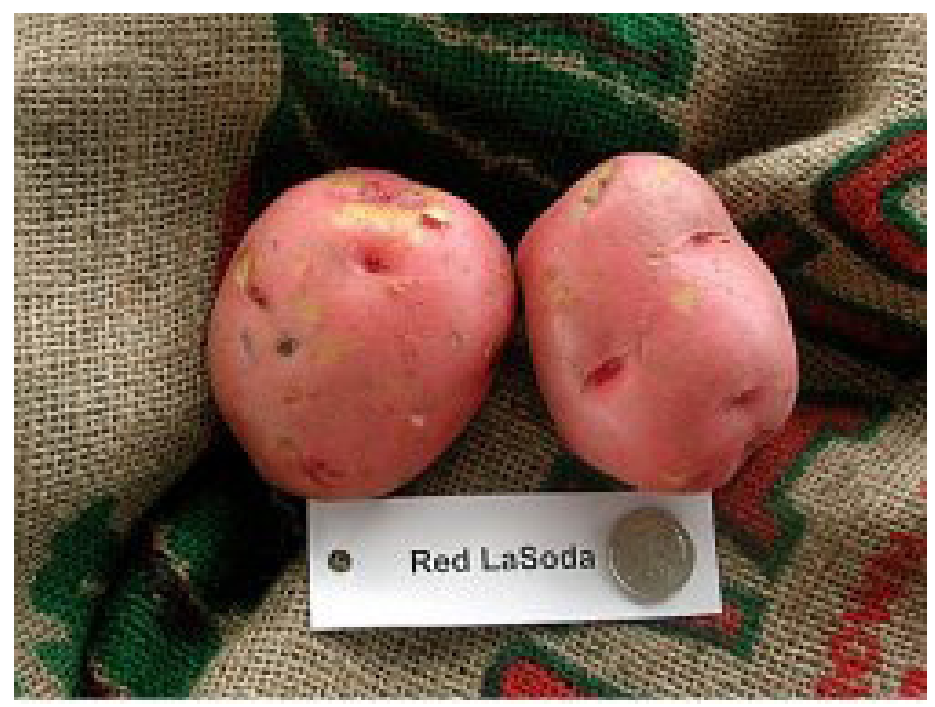

Figure 10. Red-skinned potato 'Red LaSoda'

Credits: C. Hutchinson

'LaRouge' (Fig. 11) is the current red-skinned standard variety grown in southern Florida. It produces a moderate to high yield of tubers. The mostly round tubers have relatively deep eyes and moderately smooth skin texture. The bright red skin color and the good boiling qualities make 'LaRouge' a popular variety throughout the state.

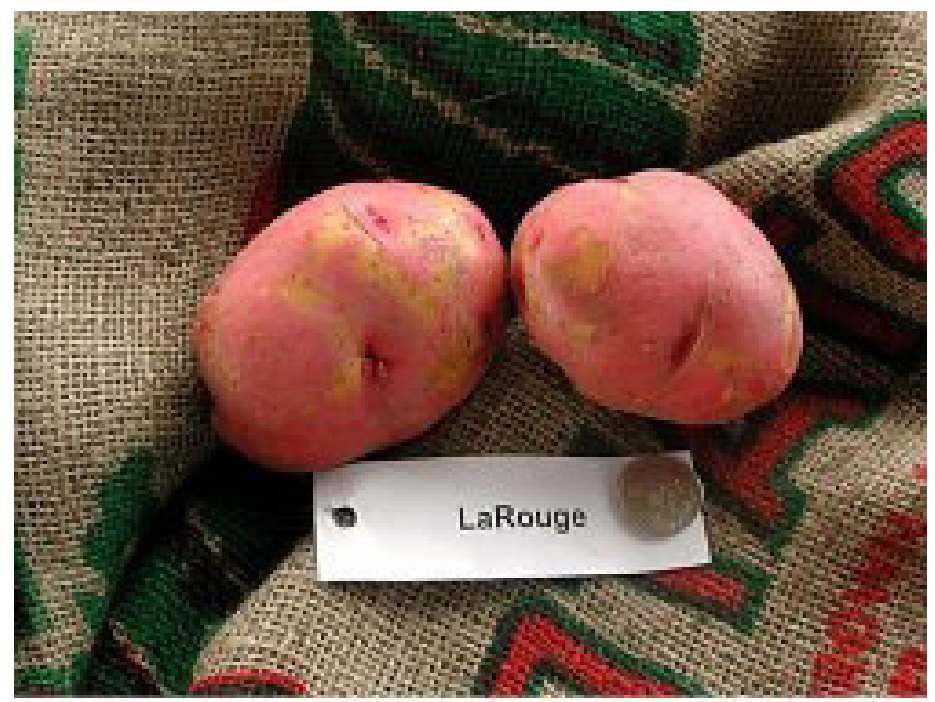

Figure 11. Red-skinned potato 'LaRouge'

Credits: C. Hutchinson

\section{Russet Potatoes}

Florida does not have a standard russet variety for commercial production. When choosing a russet variety for the home garden, select varieties that mature relatively early so the potatoes can be harvested during the cooler months of the year. One relatively short-season russet that matures approximately $100-115$ days after planting in Florida is 'Russet Norkotah' (Fig. 12).

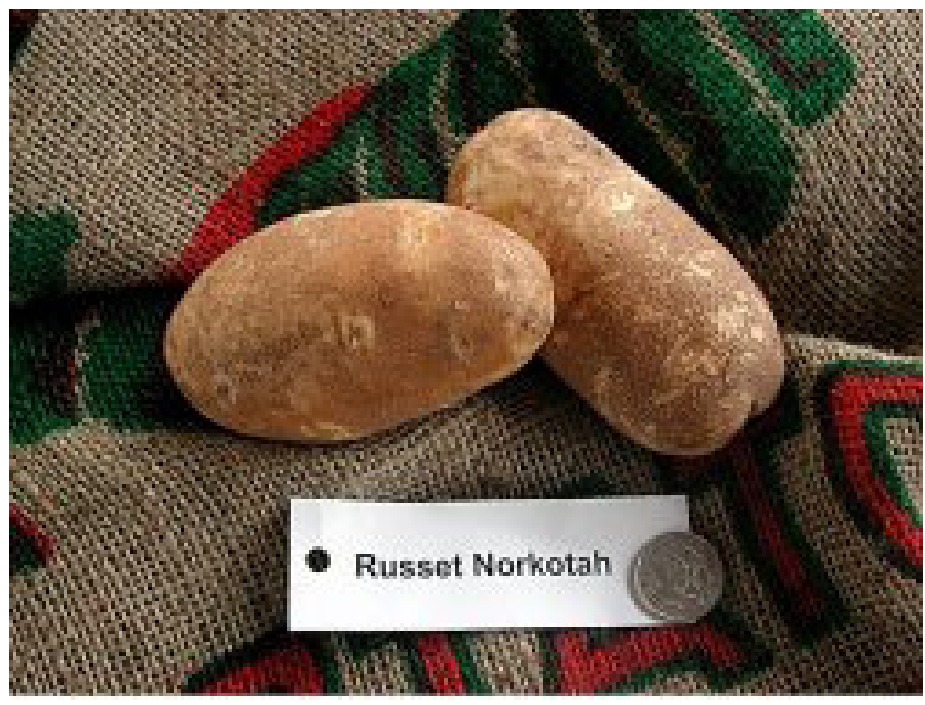

Figure 12. Russset potato variety 'Russet Norkotah' Credits: C. Hutchinson

This potato produces high yields of brown- to dark brownskinned tubers. The tubers have a heavy russet or netted skin texture. Tubers are oblong to long with a shallow to intermediate eye depth. This variety makes an exceptional baking potato.

\section{Exotic Potatoes}

Many new and exciting potato varieties are now available through reputable catalog and Internet garden supply companies. Do not hesitate to try new varieties and share them with friends. It is important to purchase varieties that mature early so that they can be planted and harvested in the cooler months of the year. These varieties include blue/ purple flesh (Fig. 13) varieties and fingerling types. Part of the fun of home gardening is exploring unusual varieties that cannot be purchased in the supermarket, and the 'All Blue' potato is a fun one to try. They are a late-season maturing potato with a deep blue skin and flesh. They also produce blue flowers. Consumers prefer to use this variety in potato salads or for baking. They also have excellent storage potential.

In addition to existing blue-fleshed and purple-skinned potatoes, new exotic varieties are being developed. These selections, originating from several South American countries, vary in size and shape, with some very unique and exciting skin and flesh colors (Figs. 14 and 15). Smaller potatoes take less time to cook, saving time and effort. In addition, the introduction of new flesh colors can increase nutritional content. For example, potatoes with a bright orange flesh have more carotenoids (Fig. 14) and those with red pigments have more anthocyanins (Fig. 15), both of which have health benefits. 


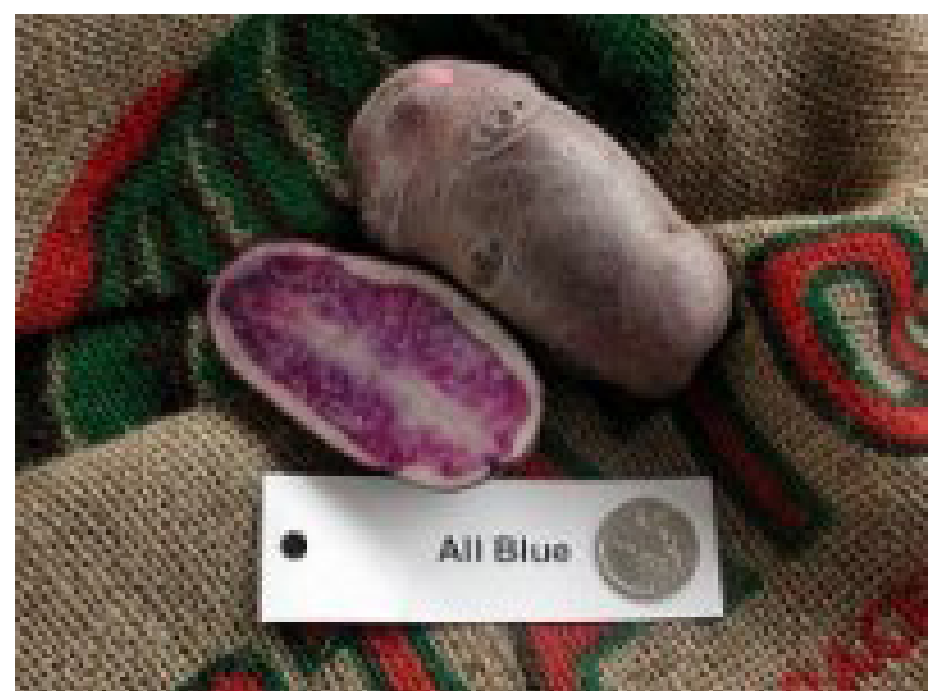

Figure 13. 'All Blue'

Credits: C. Hutchinson

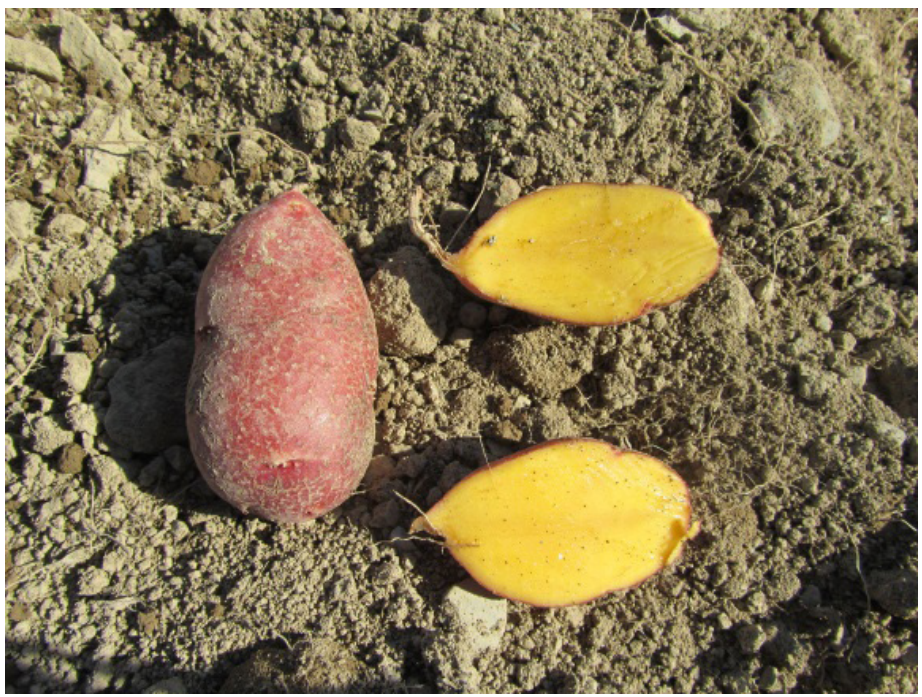

Figure 14. Red-skin yellow-flesh potato

Credits: C. Christensen

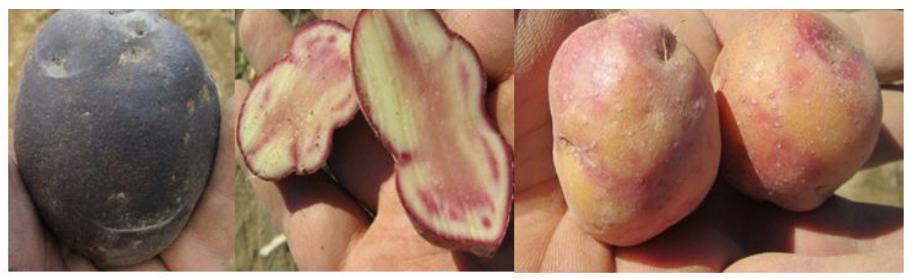

Figure 15. Examples of exotic potatoes that are not yet available commercially.

Credits: C. Christensen

\section{Planting}

\section{Soil Preparation}

To grow a healthy potato crop, the soil must be properly prepared before planting. Since potatoes prefer a loose, well-drained, slightly acidic soil ( $\mathrm{pH} 5-6$ ), little needs to be done in many Florida soils. However, potatoes do not grow well in flooded conditions. Care must be taken to ensure that the root zone has adequate drainage. This includes areas of the garden that are subject to periodic flooding. To enhance drainage, beds should be formed in hills at least 10-12 in. above the level of the soil to ensure that plants are above any standing water and that water sheds off of the beds. In well-drained soil, the addition of organic matter (i.e., compost, green manure) aids in water retention and contributes essential nutrients as it decomposes. In Florida, organic matter should be added each year because it breaks down quickly in the hot and humid subtropical climate.

\section{Fertilization}

Potato plants are heavy feeders and require adequate nutrition throughout the growing season once they have sprouted and exhausted resources within the original seed piece. In order to determine what kind and quantity of nutrients should be applied to the soil, the soil nutrient status should be tested by a qualified laboratory (http:// soilslab.ifas.ufl.edu/). If you have questions, contact your county Extension office personnel for local fertilization recommendations. Your county agent can help you interpret soil test results and determine what nutrients are deficient in the soil.

In general for Florida soil conditions, nitrogen and potassium must be added each potato season. Further, nitrogen and potassium are typically applied in at least two applications during the season. Half of the fertilizer should be applied at planting and the remainder applied during the season. More fertilizer may be necessary during periods of heavy rainfall. Based on University of Florida fertilizer guidelines, about $0.75 \mathrm{lb}$. of nitrogen and about $0.5 \mathrm{lb}$. of potassium are required per $100 \mathrm{ft}$. of row at planting. This is roughly equivalent to $7.5 \mathrm{lb}$. of a 10-0-10 complete fertilizer at each application. Any recommended phosphorus or other nutrients should be mixed in the soil at planting.

The remaining nitrogen and potassium fertilizer $(0.75 \mathrm{lb} . \mathrm{N}$ and $0.5 \mathrm{lb}$. K per $100 \mathrm{ft}$. of row) should be placed in a band about 4-6 in. to either side of the plant approximately 3-4 weeks after planting. This stage of planting is also referred to as the 6-8-in. stage in which emerged plants are 6-8 in. tall. The fertilizer should be applied at the surface and covered with soil.

\section{Seed Piece Preparation}

The potato tuber is the plant "part" required to grow a new potato plant. When a piece of the tuber is planted, it is called a "seed" potato. Only certified seed potatoes should be planted in the home garden. Certification ensures that the seed tubers are free of disease and viruses. Certified seed can be obtained from a number of reputable garden 
supply stores. Do not purchase potatoes from the grocery store to plant in the home garden. These may carry harmful potato diseases that can hurt crop growth. Tubers at the grocery store may also be treated with sprout inhibitors that may prevent establishment of the young plant. In addition, potato varieties (i.e., red or white skinned) are not labeled in the grocery store, making it difficult to identify particular varieties to grow in the home garden.

Potato tubers have buds known as eyes (Fig. 16) on the skin surface from which new plants grow (sprout). Tubers are ready to cut into seed pieces when one or more of the eyes begins to sprout. However, they can be cut before the eyes sprout. Cutting the potato into seed causes more eyes on the seed to sprout.

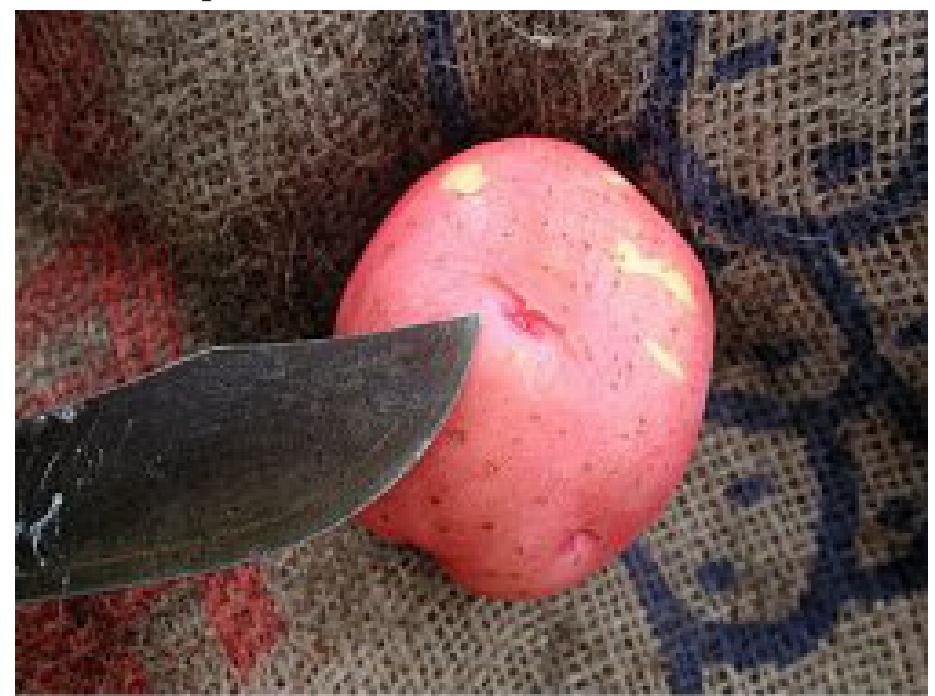

Figure 16. Eye on a red-skinned potato tuber Credits: C. Hutchinson

Sprouting of the eyes indicates that the tuber is no longer dormant. Potato tubers are naturally dormant for a period of time after harvesting. Dormant tubers can be stored for a few days in the light at room temperature to break dormancy. Do not store tubers in direct sunlight.

Seed potatoes should be cut so that each piece is about the size of an egg (2-2.5 oz.) with at least one eye per seed piece (Fig. 17). Try to make as few cuts as possible when cutting seed pieces, and ensure you have a clean blade to prevent contamination. Cut seed pieces should "heal" before planting. To heal a cut tuber, leave the tuber in a cool $\left(60^{\circ} \mathrm{F}-65^{\circ} \mathrm{F}\right)$, dark, well-ventilated place for 1 or 2 days. Seed pieces can be planted directly after cutting, but the risk of rot before sprouting is increased. Typically, $1 \mathrm{lb}$. of potatoes generates about six to eight seed pieces.

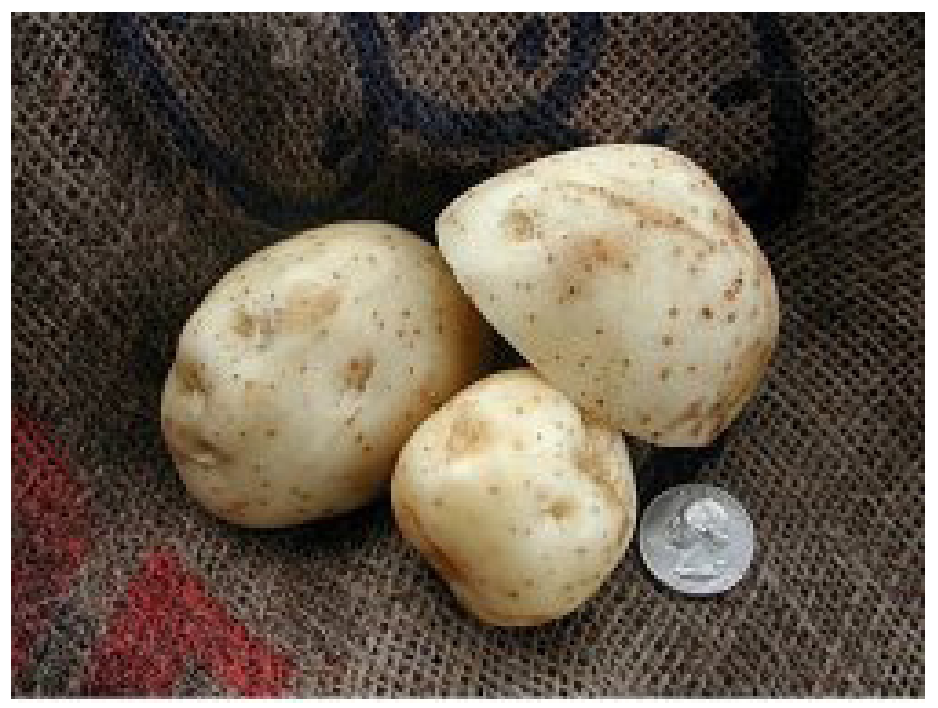

Figure 17. 'LaChipper' potatoes demonstrating appropriate seed piece size. Small tubers can be planted without cutting.

Credits: C. Hutchinson

\section{Plant Spacing}

Plants should be spaced at about 6-8 in. within the row with at least $36 \mathrm{in}$. between rows. Seed pieces should be planted 4 in. below the soil surface. Seed pieces should be planted with the cut side down and eyes (or sprouts) facing up.

\section{During the Growing Season}

Potatoes growing in the garden need periodic attention. This attention determines the quality and quantity of tubers at the end of the season.

\section{Hilling}

Hilling is the act of adding soil to the top of the potato row. Since the seed piece was only planted 4 in. below the soil surface, new potato tubers could push up above the soil surface. These exposed tubers turn green in the sun and are inedible (see Nutrition section). To prevent sunburned tubers from forming, add about $2-3$ in. of soil on the potato row when the sprout emerges from the soil. Soil can be moved from the furrows between rows and used for hilling.

\section{Irrigation}

In Florida, potatoes are typically grown during the drier season of the year (i.e., winter and spring). As a result, supplemental irrigation may be required to provide plants with an adequate amount of water. Moderate soil moisture levels should be maintained throughout the season. Care must be taken not to overwater because potato roots do not grow well in overly moist soils. In addition, fertilizer can be washed out of the root zone, making it unavailable to the plant. Small plants have a smaller root zone and require 
less water than mature plants. Water applications should be adjusted accordingly. Rough-skinned and/or knobby tubers can result when soil moisture levels swing from low to high or high to low over a short period of time during the season. Overwatering promotes root and tuber decay while underwatering can prohibit tuber formation or cause irregularly shaped tubers

\section{Weeds}

Weeds can compete for light, water, and nutrients, reducing potato yield. Weeds also can be hosts for insects and diseases. Mulches (either plastic or organic) can be used to suppress weeds. However, for potatoes in the home garden, hand cultivation (tilling soil using a hoe) is an effective technique. Care should be taken not to injure the potato plant, including its shallow root system and the tubers near the soil surface. If herbicides are used, be sure they are labeled for use in potatoes. Always follow the instructions on the label.

\section{Insects}

Insect damage can severely reduce tuber yields. Insects that can cause injury to potato plants include Colorado potato beetles (Figs. 18-20), flea beetles, aphids, leafhoppers, and wireworms (tubers). One of the best preventative measures against insect-related issues is crop rotation. This means that potatoes should only be planted in the same location of the garden every 3 years.

Removing weeds also helps control insects by removing their habitat. For larger insects, picking the insects off the plants by hand can work for smaller plantings. For large plantings, pesticides are available for use in the home

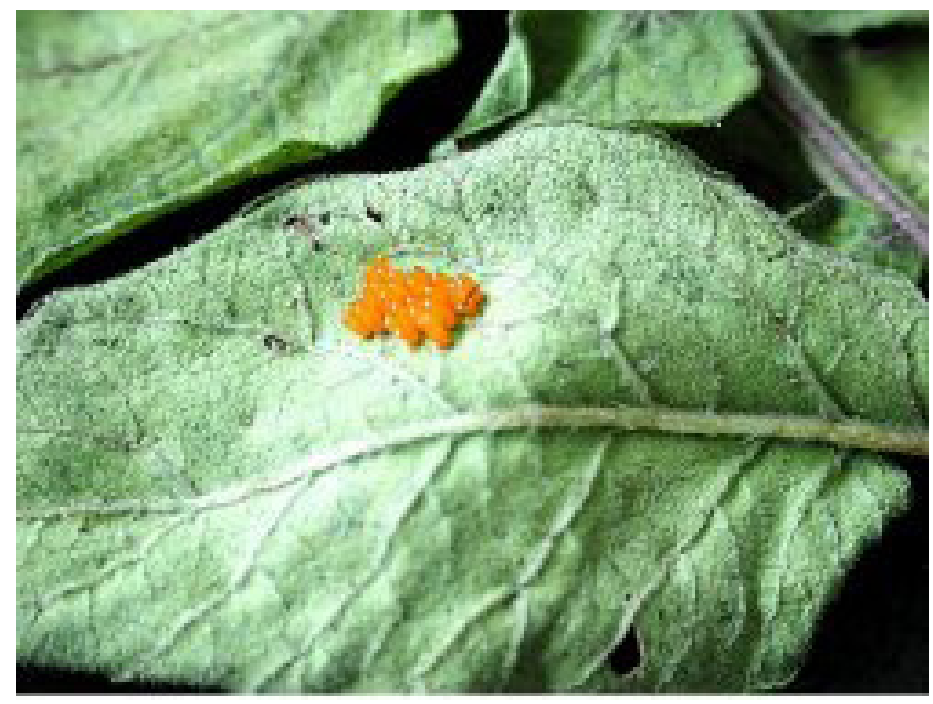

Figure 18. Colorado potato beetle egg mass Credits: C. Hutchinson

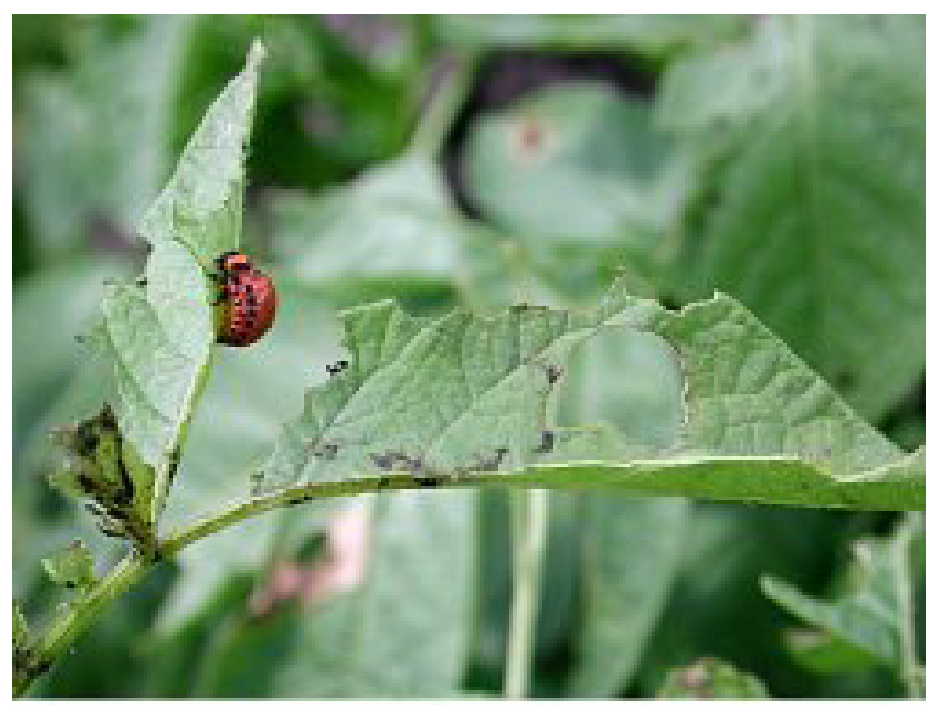

Figure 19. Immature Colorado potato beetle Credits: C. Hutchinson

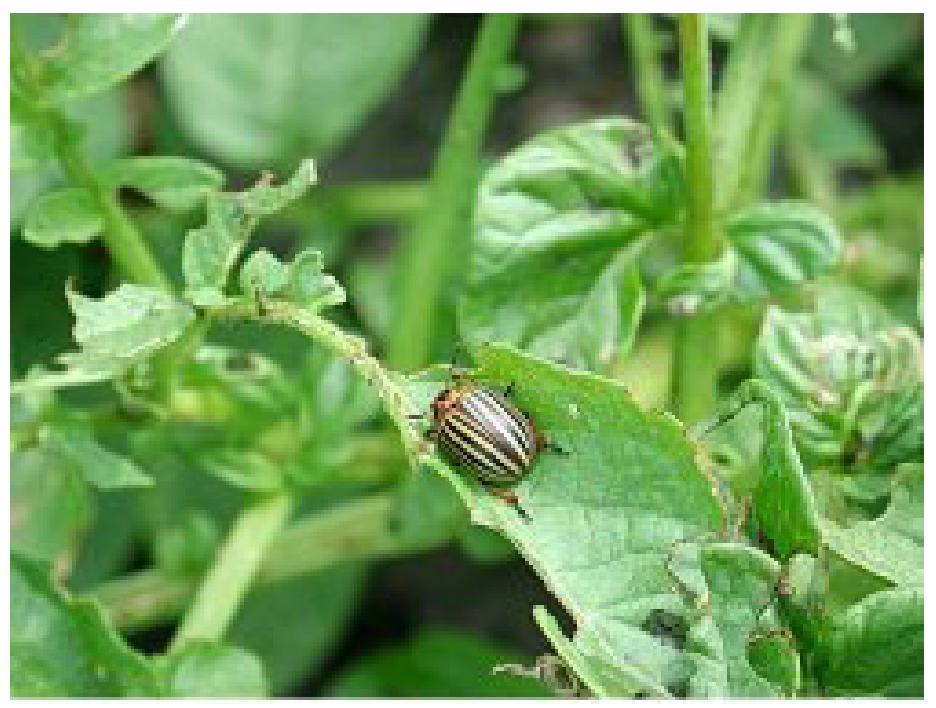

Figure 20. Mature Colorado potato beetle Credits: C. Hutchinson

garden. If using pesticides in the home garden, follow all label instructions and pay attention to all cautions and warnings.

\section{Diseases}

As with any other crop, plant diseases can injure potato plants and tubers. Some typical fungal diseases that are common in Florida potatoes are early blight (Alternia solani), late blight (Phytophthora infestans), and Rhizoctonia. In Florida, early and late blight cause the most injury to plant tissue. Rhizoctonia can attack both stems and tubers. It can rot the plant at the soil line or cause raised black spots on the tubers.

Leafroll and mosaic viruses can also injure the potato plant. Symptoms include stunting, leaf curling, and a general yellowing of the plant. Plants suspected of having a virus 
should be removed from the garden. Another noticeable virus is the tobacco rattle virus, which causes corky ringspot in tubers (Fig. 21). This virus is transmitted by the stubby-root nematode (Trichodorus obtusus Cobb) and causes a lesion on the tubers. Plant-parasitic nematodes are microscopic worms that live in the soil and feed on plant roots.

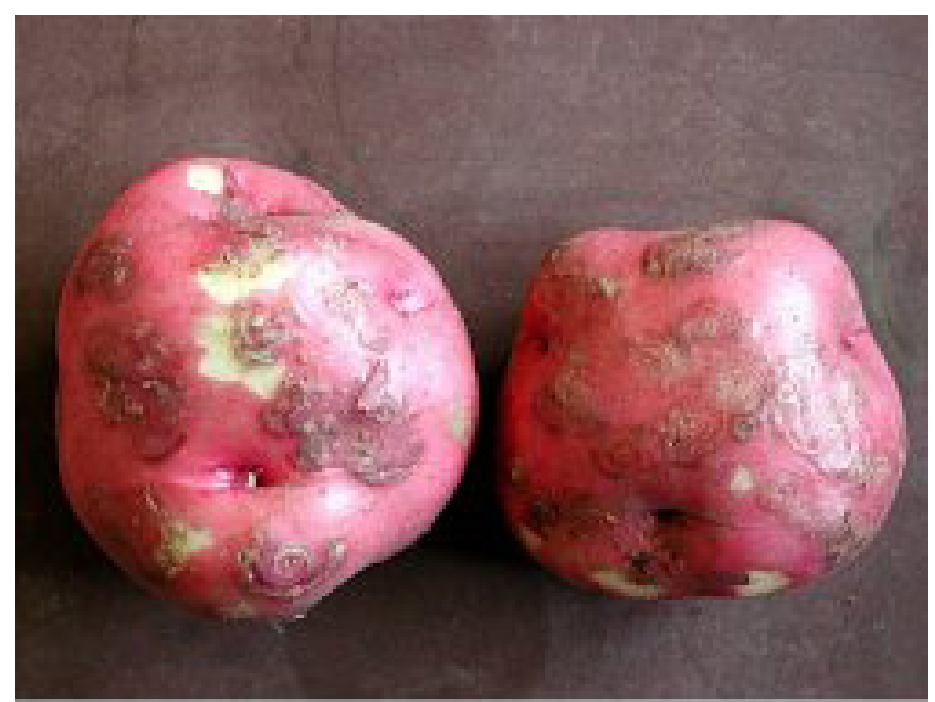

Figure 21. Red potatoes with corky ringspot viral lesions. Virus is transmitted by the stubby-root nematode.

Credits: C. Hutchinson

Many fungal diseases are spread by water. The garden should be watered in the morning to provide time for leaves to dry before evening. Avoid walking through the garden while potato leaves are wet. Alternatively, water can be applied in the furrow between raised potato beds. This reduces the amount of water present on the leaves and reduces disease incidence.

Planting certified clean seed potatoes can also help prevent disease. Destroying piles of rotten potatoes, plants, and other crop residue can help reduce sources that harbor diseases. As with weeds and insects, fungicides are available to help control certain diseases. Label instructions and all cautions should be observed when using pesticides.

\section{Inclement Weather}

Potato plants should be protected during the growing season from flooding conditions. At no time should plants be allowed to remain in standing water. This can cause rot, reduce yields, and if severe enough, cause plant death. Freezing temperatures can also damage potato plants. Although the potato plant is tolerant of cool weather, it cannot handle temperatures below freezing $\left(32^{\circ} \mathrm{F}\right)$. Very small plants (3-4 in.) can be covered with soil if freezing temperatures are forecast. Larger plants can be covered with freeze protection fabric when freezing temperatures are forecasted. These materials should be removed as soon as temperatures warm above freezing to prevent injury to the plant.

\section{Harvest and Storage Vine Killing and Harvest}

Most potatoes are ready for harvest between 80 and 115 days after planting. To harvest, carefully dig potatoes and remove them from the root system of the plant. Discard the seed piece if it is remaining on the plant and any green tubers (Fig. 22). If the potatoes will be stored after harvest, the plant should be allowed to die (mature) before harvest. Harvest the tubers approximately 2-3 weeks after the plant has died. If a plant has not begun the maturation stage on its own, it can be induced by killing the tops of the plant. For the home gardener, this can be done mechanically by either cutting the plants at the soil surface with pruning shears or a knife. The top of the potato plant can then be discarded. Leave the potatoes buried for 2-3 weeks after removing the tops so that the tubers can mature. Cover any exposed tubers with soil. The mature tuber has a tough skin that cannot be easily removed when rubbed.

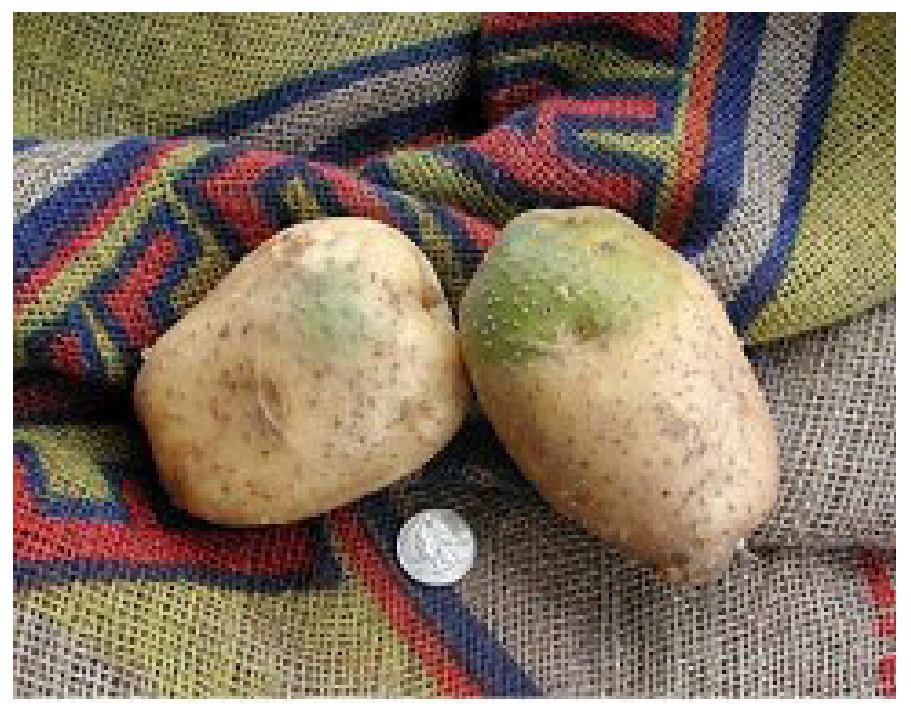

Figure 22. Green tubers should be removed prior to storage and discarded.

Credits: C. Hutchinson

A mature tuber can be stored for much longer than an immature tuber. To harvest potatoes, carefully dig below the potatoes with a shovel or spading fork and lift the potatoes (Fig. 23). Shallow digging may damage the tubers and limit their storage life.

\section{Storage}

Keep potatoes in a cool $\left(60^{\circ} \mathrm{F}-65^{\circ} \mathrm{F}\right)$, dark, well-ventilated place for 10-14 days after harvest to allow cuts and bruises to heal. Then move potatoes to a final storage location with 


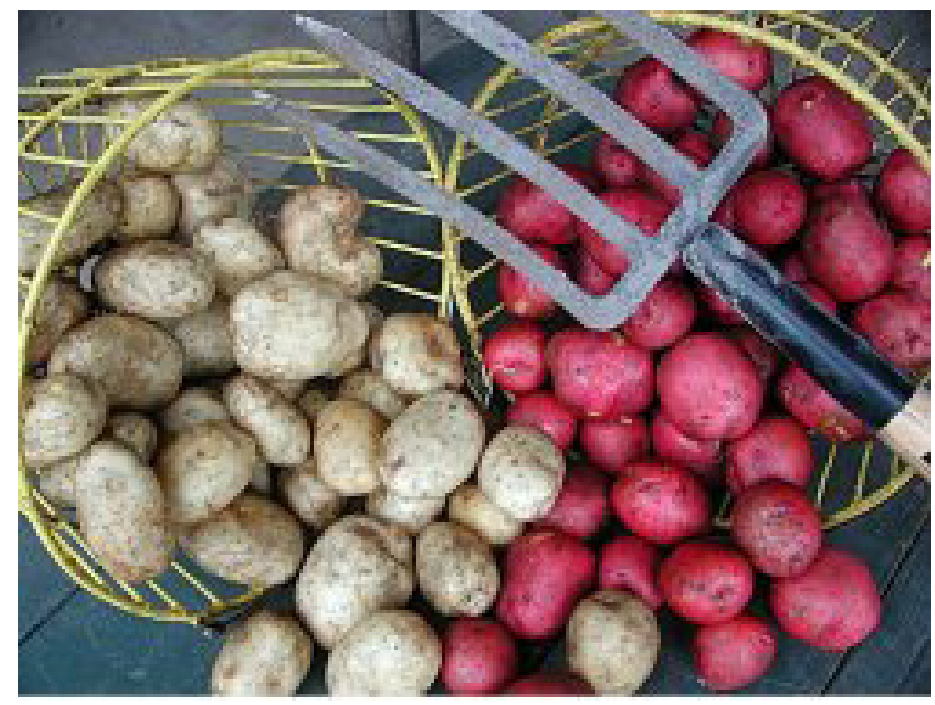

Figure 23. Baskets of potatoes and a potato fork used for harvesting Credits: C. Hutchinson.

a high relative humidity, good aeration, and cool temperatures $\left(38^{\circ} \mathrm{F}-40^{\circ} \mathrm{F}\right)$. At warmer temperatures, the tubers may sprout. Be sure to remove any damaged or rotten potatoes prior to placing them in long-term storage as they will greatly shorten the storage life of the rest. Washed tubers should be allowed to dry thoroughly before storing. Under proper conditions, potatoes can store for 3-6 months or more.

\section{Nutrition}

Potatoes are a great addition to a healthy diet given their high nutritional content. One medium potato (about $2.5-3$ in. long) is fat free and contains about 150 calories, $4 \mathrm{~g}$ of protein, and $34 \mathrm{~g}$ of carbohydrate. Included in the carbohydrates are $3 \mathrm{~g}$ of dietary fiber, about half of which is from the skin. Potatoes are an excellent source of vitamin C, providing more than $30 \%$ of the recommended daily intake in just one medium potato. Potatoes are very low in sodium and a great source of potassium, higher than many fruits and vegetables. Orange-fleshed sweet potatoes are particularly good sources of carotenoids. Other important nutrients found in smaller amounts include B vitamins, calcium, iron, phosphorus, and zinc.

Foods low in sodium and high in potassium are recommended for the prevention of high blood pressure, a primary risk factor for heart disease. Few Americans consume adequate potassium and most consume excessive sodium. A potato a day may not only help to lower blood pressure but may also reduce the risk of developing kidney stones and help to prevent bone loss.

\section{Toxicity}

One should always avoid eating green potatoes. Green potatoes have high levels of a toxin called solanine (glycoalkaloid), which has a bitter taste. The toxin is found throughout the plant but especially in unripened potatoes, green potatoes, and in the new sprouts. It is toxic even at very low levels. Potatoes can "green" in the field, in storage, and at home when exposed to the light.

\section{Additional Information}

Further websites of interest for Florida potato production can be found by going to http://edis.ifas.ufl.edu and typing "potato" into the keyword box. 